\title{
PRODUCTI0N
}

Production Planning \& Control

\section{Decisional behaviours in enterprise networks}

\section{Valérie Botta-Genoulaz \& Thibaud Monteiro}

To cite this article: Valérie Botta-Genoulaz \& Thibaud Monteiro (2010) Decisional behaviours in enterprise networks, Production Planning \& Control, 21:6, 525-527, DOI: 10.1080/09537287.2010.488926

To link to this article: http://dx.doi.org/10.1080/09537287.2010.488926

\section{Published online: 01 Oct 2010.}

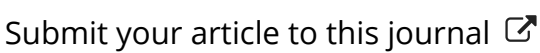

Џll Article views: 158 


\section{EDITORIAL}

\section{Decisional behaviours in enterprise networks}

More and more extended enterprise environment requires a larger control of decision-making types. This control has became complex especially since companies have evolved in a context where decisionmaking is often antagonistic. In order to maintain local and global performances, it is necessary to propose methods and tools that allow one to analyse, at the same time, local behaviour impacts and coordination modes among the whole supply chain. It is then important to develop techniques or methods that can model decision-making modes, coordination mechanisms, collaborative behaviours and informationsharing practices.

The objective of this special issue is to bring together the most up-to-date research in the modelling and performance evaluation of decisional behaviours in enterprise networks or supply chain environments.

These problems related to performance and optimisation of supply chain control concern both the academic and industrial communities. The international conference on Information Systems, Logistics and Supply Chain (ILS), organised on 27-30 May 2008 in Madison, WI (US), addressed a broad range of topics related to supply network, logistics operations management, supply chain management, and optimisation and information systems. Participants had the possibility to discuss emerging industrial issues, share common practices and recent research development and identify research opportunities in the area of Supply Chain Management. The international conference on Modelling, Optimization and Simulation of Systems (MOSIM), organised on 31 March and 1-2 April 2008 in Paris, also addressed topics related to decisional behaviours in enterprise networks in two special sessions.

Six of eight articles published in this special issue of Production Planning \& Control were selected among the best contributions in this topic, discussed at ILS and MOSIM conferences, re-written and re-reviewed. Two others articles came from invited authors who are known as experts in this field. Article contents are promising and present substantial advances in enterprise network research to overcome complexity and decision interactions by providing new decisionmaking modes, coordination mechanisms, collaborative behaviours and information sharing practices in a wide variety of contexts and applications.

The first part of this issue is dedicated to conceptual works on relationship management in a collaborative context.

In the first article, 'B2B relationship management: a framework to explore the impact of collaboration', Derrouiche et al. propose an integrated framework which is able to characterise a dyadic collaborative relation and evaluate the performance of this relation according to several attributes. This framework is based on two levels dedicated respectively to the collaboration context and to its performance. The attributes are 'climate of the relation', 'structure of the relation', 'information technologies (IT) used', 'lifecycle of the relation' for the former and 'the perceived satisfaction of the relation' and 'its perceived effectiveness' for the latter. An empirical study on several manufacturing companies was undertaken to validate this framework.

The second article, 'A review of Vendor Managed Inventory (VMI): from concept to processes' by Marquès et al., proposes an analysis of this modern supplier-customer relationship to monitor the customer's inventory replenishment. Based on a large literature review, they propose a unified view of VMI via three main processes: Partnering Agreement, Logistical Agreement, Production and Dispatch. They emphasise the degrees of freedom available to the supplier and distinguish two types of VMI: Dispatch-VMI, centred only on delivery decisions, and Integrated-VMI, integrating both production and delivery decisions.

The second part of this issue is dedicated to collaborative decisional analysis based on simulation in order to optimise global performance of network.

In the third article, 'DSOPP: a platform for distributed simulation of order promising protocols in supply chain networks', Kiralp and Venkatadri propose an optimisation-based multi-agent decision support platform for integrated order promising 
and production planning in multi-enterprise supply chains. Experiments are done on a distributed network with two individual supply chain networks, a supplier network and a customer network in order to analyse the effects of different parameters on individual supply chain networks and the multi-enterprise network. This platform provides the decision-maker with a useful tool to see the relations and behaviour of individual supply chain networks in a multi-enterprise network.

In the context of unexpected orders, the fourth article, 'Evaluation model framework based on simulation for enterprise network negotiation mechanisms' by Monteiro et al., proposes architecture based on multi-agent system to ensure a global coherence and the convergence of decision processes. This architecture has been applied to a particular problem in which enterprises are searching complementary resources (stocks, production capacities, components and/or transport capacities) in order to deal with unexpected orders. Its negotiation mechanisms allow finding a good equilibrium between the quality of the co-decisions and the allocated time to keep agility in enterprise networks.

The specific context of franchise bakery network is analysed by Fenies et al. in 'A decisional modelling for supply chain management in franchised networks: application in franchise bakery networks'. They propose a two-level modelling to evaluate/optimise supply chain flows in a franchise network: the first one reproduces the running supply chain; results are used in a second model for MILP optimisation; then, for the opening of a new outlet, generated cash flow is analysed to choose between a company owned and a franchise. An application is done on bakery networks, which are made up of a network of franchises, a network of company-owned outlets, and industrial factories. The proposed approach shows how an operator of a mixed network can maximise his own cash flow in developing outlets.

The last part of the issue is dedicated to collaborative scenario analysis. Those works analyse the impact of information sharing and collaborative behaviours on supply chain performances.

The sixth article, 'Simultaneous configuration of platform products and manufacturing supply chains: comparative investigation into impacts of different supply chain coordination schemes' by Zhang et al., analyses three coordination scenarios of a supply chain that consists of one manufacturer and multiple suppliers: Non-Interactive-Supplier, Non-CooperativeSupplier, and Cooperative-Supplier. Simulations are undertaken on a near-real-life industrial case of automobile products. Their results show how a higher level of integration is profitable for the supply chain system.

The seventh article, 'Statistical distribution of the savings induced by sharing demand information in a two-company Beer Game' by Moyaux and Baboli, investigates the impact of information sharing on network performances. Three replenishment policies are analysed: no information sharing, slow information sharing and instantaneous information sharing. Their impact on inventory and backorder are discussed through beer game experiments. The Nash equilibrium allows the authors to conclude that companies have incentives to use information sharing because such collaboration saves money.

The last article of this issue is dedicated to analyse how collaboration can reduce the environmental logistic footprint. Ballot et al. in 'Reducing transportation $\mathrm{CO}_{2}$ emissions through pooling of supply network: perspective from a case study in French retail chains' explore the link between a collaborative behaviour and reduction of $\mathrm{CO}_{2}$ emission. Logistical data from real industrial situations are used to test several collaboration scenarios. The authors explore the potential saving of $\mathrm{CO}_{2}$ emissions, as well as delivery frequencies and collaboration viability.

The guest editors would like to thank the authors for their valuable contributions reserved for this special issue and the reviewers for their precious referee work.
Valérie Botta-Genoulaz Professor University of Lyon LIESP, INSA-Lyon F-69621 Villeurbanne cedex, France valerie.botta@insa-lyon.fr

Thibaud Monteiro Assistant Professor University of Lyon LASPI, University of Saint Etienne F-42334, Roanne, France Costeam project, INRIA Nancy-Grand Est F-57045 Metz, France thibaud.monteiro@univ-st-etienne.fr 


\section{Notes on contributors}

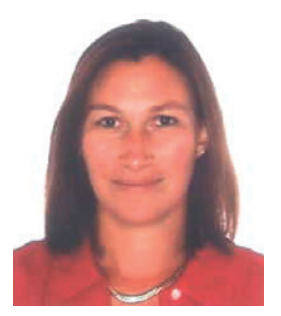

Valérie Botta-Genoulaz is a Professor in the Industrial Engineering Department of the National Institute of Applied Sciences of Lyon (INSALyon), University of Lyon, France. After 6 years' experience in industry, she obtained a $\mathrm{PhD}$ in Production Management (University of Lyon), and was certified application consultant 'Production Planning' for SAP

$\mathrm{R} / 3$. She does research in the Laboratory of Information Science for Enterprise and Production Systems, and her interests include operation planning, supply chain management, information sharing, ERP systems, collaborative practices, and their impacts on enterprise performance. She co-chairs the steering committee of the International Conference on Information Systems, Logistics and Supply Chains.

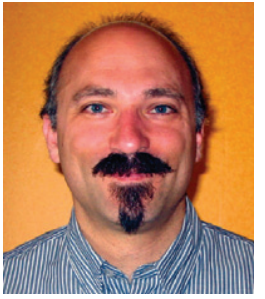

Thibaud Monteiro is currently Maître de Conférences at the University of Saint-Etienne. He manages the Healthcare Logistic axis of the Laboratoire d'Analyse des Signaux et des Processus Industriels (LASPI) and is also an associate member of the INRIA Costeam team. He received the engineer degree in 1998 from the National Engineering School of Tarbes (ENIT). He obtained his $\mathrm{PhD}$ degree in Industrial Engineering from Institut National Polytechnique of Grenoble (INPG) in 2001 and his HDR from the University of Metz in 2009. His main research interests include operational supply chain management for industrial and healthcare system, performance measurement and collaboration modelling. 